\title{
NASA Education and Educational Technologies Exemplified by the Space Weather Action Center Program
}

\author{
Norma Teresinha Oliveira Reis ${ }^{1}$, Claudio André ${ }^{1}$, Troy D. Cline ${ }^{2}$, \\ Timothy E. Eastman ${ }^{3}$, Margaret J. Maher ${ }^{4}$, Louis A. Mayo ${ }^{2}$, and Elaine M. Lewis ${ }^{2}$ \\ ${ }^{1}$ Brazilian Ministry of Education - MEC, Brazil \\ normareis@mec.gov.br, claudio.andre@mec.gov.br \\ ${ }^{2}$ Honeywell Technology Solutions Inc., USA \\ troy.d.cline@nasa.gov, \\ louis.a.mayo@nasa.gov, elaine.m.lewis@nasa.gov \\ ${ }^{3}$ Wyle Information Systems, LLC, USA \\ timothy.e.eastman@nasa.gov \\ ${ }^{4}$ NASA Goddard Space Flight Center, USA \\ margaret.j.maher@nasa.gov
}

\begin{abstract}
We explore here the Space Weather Action Center (SWAC) Program, as an example of NASA initiatives in education. Many human activities in space can be disrupted by space weather. The main objective of this program is to enable students to produce space weather forecasts by accessing current NASA data. Implementation of the SWAC Program requires: technological resources, online materials, and systematic work. Instructional guides, materials and methods are explained on the Space Weather Action Center Web site (http://sunearthday.nasa. gov/swac). Ultimately, students' forecasts can be presented through a variety of accessible media including inexpensive video editing software and/or already existing school-based broadcast studios. This cross-curricular program is targeted to middle and high school and can be applied in almost all educational contexts as the number of schools with computer and internet access increases worldwide. SWAC is a pioneer initiative that contributes to fostering student interest in STEM and promotes their intellectual autonomy. Through SWAC, they get to act like real scientists by accessing, analyzing, recording, and communicating space weather forecasts in a professional approach.
\end{abstract}

Keywords: STEM education, education technologies, space science education.

\section{Introduction}

Scientific and technological development generates socioeconomic benefits and sovereignty [1]. For this reason, among other strategies to foster advances in those sectors, governments have been concerned with the promotion of public policies to strengthen Science, Technology, Engineering and Mathematics (STEM) taught in 
schools, as a vehicle to encourage careers in those areas. Moreover, STEM education plays a vital role in promoting effective inclusiveness of citizens in a societal fabric permeated by processes/products/services requiring of individuals a certain level of STEM literacy [2]. Currently, a growing number of students have access to computer, internet, and other technologies. Nevertheless, the success of STEM education is well below that expected, as shown by both national and international examinations, such as the Programme for International Student Assessment - PISA [3]. Indeed, STEM education has been facing several challenges, such as: a) theoretical-methodological inadequacy; b) teacher pre- and in-service preparation; c) quality didactic books and technological equipment; d) fallacious pedagogical theories according to which students can learn spontaneously, without practical experience yet with overly-abstracted contact with theory; e) difficulties to work in an interdisciplinary approach; f) rapid changes in the world of knowledge [4]. This scenario claims for pedagogical approaches that adequately address STEM education concerns.

Space education is an alternative for effective STEM teaching. But what is space education anyway, and where can we find it? Space education stands for a wide range of pedagogical practices; didactic resources; subject matters; curricular and/or crosscurricular topics; formal and/or informal; systematic and/or sporadic programs/projects/activities, which take advantage of the amazement that space matters exert on students' imagination, thus capturing early interest in STEM subjects, elucidating scientific knowledge in a non-abstract approach, spreading the benefits of space programs, and ultimately encouraging STEM careers.

The National Aeronautics and Space Administration - NASA - has the largest and most complex space education program in the world. Education plays a unique role in the scope of the overall NASA mission. In this paper, we introduce NASA education and educational technologies, and present one of its state-of-the art programs, the Space Weather Action Center - SWAC.

\section{NASA Education and Educational Technologies}

Space education and outreach at NASA started as a concern towards offering societal contributions and disseminating the agency's activities. In fact, "Education and contributing to the public understanding of science have long been important components of NASA's mission." [5]. After the cold war period, space faring nations required socioeconomic benefits from their space programs, as political motivations weakened. In this framework, NASA's Office of Space Science hired education leaders and scientists to establish its own education and outreach programs (EPOs). In 1993, after getting advice from national education experts, Dr. Jeffrey Rosenthal set up an "ecosystem" for EPO. Instead of each scientist, institution, and mission pursuing EPO on its own, the new EPO programs would coordinate and amplify individual efforts so that the overall effect would be greater than the sum of its parts. The system was made of forums to coordinate EPO activities among like missions, and regional brokers/facilitators to link missions/scientists to school systems, museums, educational publishers, etc [6]. This complex structure increased scope and pedagogical impact of NASA education efforts. 
NASA education goals are aligned with wider American objectives for education. The agency aims to strengthen STEM taught in schools and to ensure that an adequate supply of scientists and engineers will be available in the future to continue NASA's explorations. NASA education takes advantage of its unique personnel, rich online and printed resources, educational materials facilities, partnerships with scholarly communities, countrywide scope, international efforts, and more, to engage individuals in STEM [7].

The NASA public policies for education are implemented through a portfolio of investments, which comprises programs, projects, activities, processes, didactic resources and education technologies targeted to students, educators, families and communities. It aims to strengthen the NASA mission by means of the achievement of its main goals/outcomes: a) contribute to the development of the STEM workforce in disciplines needed to achieve NASA's strategic goals; b) attract and retain students in STEM disciplines; c) build partnerships and linkages between STEM formal and informal education providers that promote STEM literacy and awareness of NASA's mission [8].

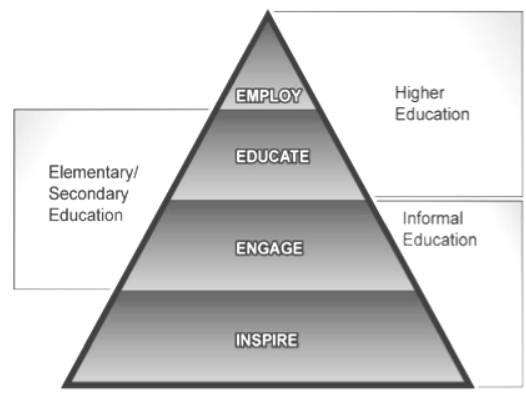

Fig. 1. Education levels of involvement of the NASA portfolio. Source: Figure 2 of the NASA Education Strategic Coordination Framework: A Portfolio Approach.

The agency's portfolio of investments covers five strategic areas: higher education; minority university research and education; elementary and secondary education; informal education; and education technology and products. Indeed, NASA supports elementary and secondary schools, universities, colleges, by providing exciting research and internship opportunities that will fuel the passion for a new culture of learning and achievement in STEM. Moreover, to strengthen STEM education, NASA will sustain professional development and research opportunities for pre-service and in-service teachers and university professors [9].

There are some criteria/principles guiding this portfolio, such as diversity, relevance, continuity, and partnerships/sustainability. Activities in the portfolio cover one or more categories of involvement:

1. Inspire: awareness of NASA's mission among the public.

2. Engage: interaction with NASA contents for a deeper understanding.

3. Educate: learning among targeted populations.

4. Employ: development of individuals who prepare for employment in disciplines needed to achieve NASA's mission and strategic goals.

Each of these categories should lead to the next. Students are inspired and engaged by means of informal and formal education activities. They could choose careers in STEM, eventually leading to employment at NASA [8].

NASA education activities are complex because there are offices of education in each of ten space centers. In addition, almost all missions have an education and outreach 
(EPO) office with specific budget to conduct mission-related educational activities. Four mission directorates cover major areas of the agency's research and development: Aeronautics Research, Exploration Systems, Science, and Space Operations. Another important component of NASA education is partnerships with national and international entities, in order to generate synergy of efforts. Quality communication, monitoring and evaluation are essential to the effectiveness of such a complex enterprise.

The agency offers a wide range of resources to both educators and students, such as online and printed resources, in-service courses for teachers, guided visits to space centers, lectures with astronauts, interaction with members of the ISS, by means of the Amateur Radio on International Space Station - ARISS (http://www.nasa.gov/ audience/foreducators/teachingfromspace/home/index.html) interactive tools such as the Digital Learning Network - DLN (http://dln.nasa.gov), the LEARN Project (http://www.cet.edu/?cat=cotf), podcasts, webcasts, and more. The main gateway to NASA educational products is the NASA's Education Home Page (http://education. nasa.gov/home/index.html), which offers curriculum support materials by grade level, type of material or subject. These materials include educator guides, classroom activities, lithographs, project brochures, video clips. Subjects include careers, earth sciences, life science, mathematics, physical science, space science, and technology [10]. Investments in educational technologies at NASA enable new learning environments using tools such as simulations, visualizations, online game playing, intelligent tutors, learner networking, e-Professional Development (e-PD), digitized building blocks of content, and so forth [8].

We will explore in this paper a program of NASA's Science Mission Directorate (SMD), devoted to space science studies by Earth-orbit and deep space observatories, spacecraft to visit other planetary bodies and robotic landers, rovers and sample return missions. This directorate develops research on Earth, heliophysics, planets and astrophysics [10]. As an example of NASA's state-of-the-art education programs, we present here the Space Weather Action Center - SWAC, a heliophysics education program, which aims to engage students into the understanding of the Earth-Sun system in a highly innovative, awe-inspiring, and content-rich pedagogical approach.

\section{Scientific Background - The Earth-Sun System and Space Weather}

The SWAC Program aims to provide an understanding of space weather. In order to contextualize space weather, some concepts related to the Earth-Sun system must be introduced. One of them is Heliophysics, the study of the Sun's activity and its effects on the interplanetary environment, the planets and other solar system bodies, and the interstellar medium. It also comprises the study of plasmas, magnetic and electric fields, and small- and large-scale electrical currents [11] Plasma is the fourth state of matter, distinct from neutral gas, liquids and solids. They are constituted by an interactive mix of charged and neutral particles, magnetic and electric fields, which exhibits collective effects and can sustain electrical currents. We live in a "Plasma Universe ${ }^{1} . "$ The space between the planets, moons, asteroids and comets, although

\footnotetext{
${ }^{1}$ Term coined by plasma physicist Dr. Anthony Perratt.
} 
apparently empty, is actually filled with plasmas, which despite being very tenuous, can have huge effects across these enormous distances [12].

Space weather is a result of the behavior of the Sun, the nature of Earth's magnetic field and space environment, and our location in the solar system. Through complex couplings, the Sun, the solar wind, and the magnetosphere, ionosphere, and thermosphere can influence the performance and reliability of spaceborne and ground-based technological systems [11]. In other words, space weather refers to the interaction of plasmas coming from the Sun (via the solar wind) with Earth's space environment. During periods of intense solar activity (solar storms) the Sun liberates excessive amounts of plasma energy. Magnetic fields near the Sun help to accelerate energetic plasmas, especially near sunspots, and the resulting outflow through the solar wind (either in the form of coronal mass ejections or solar flares) can impact Earth's space environment. Within one to four days, plasma coming from the Sun compresses Earth's magnetosphere on the dayside while the side opposite to the Sun is stretched farther out into space. Our magnetosphere tries to re-establish its original shape. Some of this plasma is filtered through the outer magnetospheric boundaries and follows Earth's magnetic field towards the northern and southern polar regions where plasma particles (especially electrons) collide with the upper atmosphere to generate magnificent auroras [12].

Some space weather effects are not so beautiful though, and can generate storms. During such storms, energetic particles and photons can threaten human activities both on Earth and in space, posing a radiation hazard for astronauts in spacewalk, and crews and passengers of aircraft. Severe geomagnetic storms can interfere with communications and navigation systems, reduce the useful lifetime of telecommunications and observation satellites. It can also disturb spacecraft orbits due to increased drag, and provoke power blackouts. Humans venturing into space need to monitor the Sun and have access to space weather forecasts to protect both themselves and their spacecraft systems. Scientists studying space weather, like meteorologists studying weather patterns in Earth's atmosphere, seek to better predict when and where space storms will happen. Predictions depend on research on the complex nature of the Sun, its heliospheric plasma environment, and the response of the Earth's magnetosphere [12].

\section{The Space Weather Action Center - SWAC}

The Space Weather Action Center - SWAC - is a nationwide education program aimed to capture students' interest for space sciences. The SWAC system focuses on leading students to master an enhanced understanding of the Earth-Sun system - specifically the interaction between solar plasmas and Earth's magnetic field and plasma environment (magnetosphere), and other ways in which the Sun affects the Earth system, by monitoring the progress of solar storms. Students assess current conditions in geospace, create a space weather report, and share their reports with peers around the world via the Web. Activities take just a few minutes per day, and combine science, technology, arts and plenty of creativity.

Its target audience is composed primarily of middle and high school students. However, SWAC data resources have also been largely used at the university level, and the program has proposed for additional resources and educational activities for 
students at the elementary level. Many of those resources are already available with the Sun-Earth Day program ${ }^{2}$. SWAC is a featured activity in that program, managed by the Sun-Earth Connection Education Forum (SECEF) at NASA Goddard. Also, SWAC materials are being downloaded from a variety of countries around the world including Brazil, Germany, Canada, India, etc.

Some basic technological devices are needed to establish a SWAC, such as a computer and internet access. In developing countries, many schools do not have such "basic" resources, but the number of schools with such resources is steadily increasing as a result of a worldwide con-

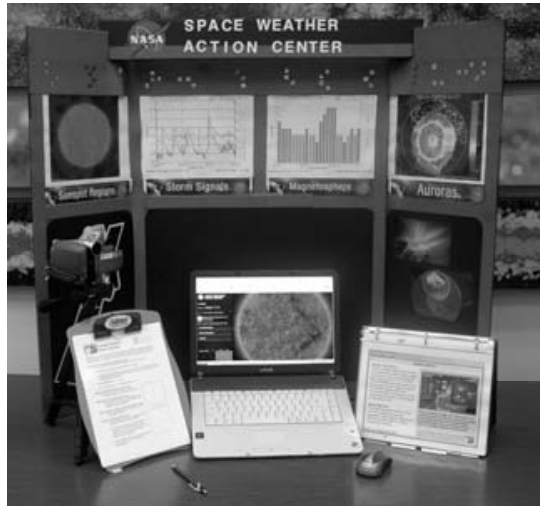

Fig. 2. SWAC Display Board constructed by students cern towards fostering digital literacy in the scope of technological inclusiveness. Hence, the SWAC Program can be applied in all developed and many developing countries.

In order to begin, the first step is the assembly of SWACs. In the second crossdisciplinary phase of the program, students access, analyze, and record NASA satellite and observatory data in real time in order to produce professional-looking space weather journal data, reports, and multimedia broadcasts. To facilitate the execution of this task, a sample script is provided on the program's Web site. In other words, the idea is to enable students to monitor space weather, and generate space weather reports analogous to terrestrial weather reports we watch on TV.

The program is based on well-defined protocols. The principle is to enable everyone to achieve roughly similar results by following the same procedures. Instructions and resources are available on the NASA SWAC Web site (http://sunearthday. nasa.gov/swac/). Basically, the Instructional Guide and the Flip Chart Guide present full explanations on how to plan and execute tasks. The Instructional Guide is a starting point to plan and construct the SWACs, also presenting background information about the Sun, along with a glossary of space weather terms and other resources. In its turn, the Flip Chart Guide includes data collection sheets, space weather data, tips, questions from the student data collection sheet, etc. At a first glance, it may seem difficult to access and analyze NASA data, but as teachers and students become familiar with those materials, it gets unexpectedly easy. There is a single link on SWAC Web site for space weather data (http://sunearth.gsfc.nasa.gov/spaceweather/), along with detailed tutorials that make it easy, simple and fast for students to collect, analyze data and prepare their reports.

SWAC is unique in that it provides step-by-step instructions and tutorials on how to access and analyze new information. The intention is to have students carrying out research, accessing data in a professional manner, and communicating results using Web and broadcast resources. During this pedagogical process, students need educators'

\footnotetext{
${ }^{2}$ For more information, visit http://sunearthday.nasa.gov/2009/index.php
} 
supervision and guidance, but simultaneously they should be encouraged to increase their intellectual autonomy, high level thinking, teamwork and communication skills because they would be asked to broadcast their results in a meaningful, objective, clear manner to the entire class. Although the focus here is space weather, the SWAC systems and architecture may be adapted to almost any other educational topic, such as environment conservation, violence in large cities, global climate change, agriculture management, and other subjects of interest to each educational community. With access to the proper data resources, student reports can be generated on any subject.

\subsection{Structure and Resources}

\subsubsection{Physical Structure}

Each SWAC should contain the following elements:

- Computer with Internet access;

- $\quad$ Display Board (Assembly Required);

- Instructional Flip Charts (Assembly Required);

- Data Collection Clipboards or Notebooks (Assembly Required).

At least one internet connection is needed to access data from the SWAC Web site. However, students not having computer and internet connection can take advantage of the supporting activities: how to build and/or use a sunspotter, understanding magnetism, and more. Schools with limited internet connectivity can still participate. If technology is limited and dedicated access to a computer is only via a teacher's computer, the teachers can access and share specific sets of data with the class on a daily basis. Students can then simply copy the data to their notebooks or maintain a classroom data folder.

It is recommended that a secure area of a classroom or a separate room be established exclusively for the SWACs. They should be placed in easily accessible spots, offering students a separate space to visit topics of interest and/or to reinforce selected skills. Having a specific place for them assures that it will not interfere in other ongoing routine classroom activities. A list of material required for the display board assembly is available on SWAC Instructional Guide.

\subsubsection{Obtaining and Analyzing Data}

A set of online didactic materials is used to orient students on how to obtain and analyze data:

a) Student Flip Charts: provide a snapshot of the four major space weather areas. Each section contains a brief overview, helpful tips and questions from the student Data Collection Sheets. Each set of flip chart cards also includes 'easy to follow' Instruction Cards, containing steps necessary to obtain, analyze and record online data, along with Information Cards, containing a variety of sample images and helpful tips on how to interpret and analyze data.

b) Data Collection Sheets: provide the necessary questions and refreshers on how to interpret necessary space weather data. A comprehension question at the bottom of each data sheet provides an opportunity for students to summarize the data and make a prediction for verification over the next several days. 
c) Space Weather Media Viewer: this observation tool is a single Web page containing live or 'near-real' time space weather data, and tutorials with stepby-step instructions on how to interpret data. Once opened, it can be kept in a separate browser tab or window for faster data access when needed.

Resources are divided into four 'color-coded' categories: sunspot regions (orange), storm signals (green), magnetosphere (blue) and aurora (purple). This color code scheme is used in all SWAC materials.

After students have collected and analyzed the data in each center, they will be ready to explore data from other links and resources readily available in the Space Weather Resources 'Additional Data' section of the Web site.

\subsubsection{Recording and Organizing Data}

A variety of tools is available to keep recorded data organized for quick review:

a) SWAC Clipboards: provide a stable writing surface that students use while collecting data. A clipboard, pencil, and a copy of the corresponding data collection sheet should accompany the station.

b) SWAC Notebooks: to eliminate the need for multiple copies of data collection sheets, download and print one set. Glue each data collection sheet to the inside cover of a separate notebook. When completed, there will be four separate data collection notebooks, one for each SWAC station.

It is recommended to keep a set of data collection sheets and/or clipboards nearby to allow students collect information required to complete their space weather news report.

\subsection{Getting the Job Done - Lights, Camera, Action!}

The first step to get started is to have students construct their SWAC display boards, containing drawings, pictures, and words related to space weather topic(s). It encourages an artistic approach and a sense of student ownership. Four areas should be contemplated, corresponding to major space weather topics: sunspot regions, storm signals, magnetosphere, and auroras. There are three assembly options: a) Single Classroom Display Board: includes components from all four areas of SWAC; b) Four Separate Display Boards: one display board for each section of SWAC; c) Classroom Bulletin Board Display: a large bulletin board display featuring the dynamic Sun and solar storms affecting the Earth's magnetosphere. The bulletin can be divided into four sections, corresponding to the four sections of SWAC.

Students use action centers to access imagery and data from NASA databases and analyze them by following instructions established on the previously mentioned materials. Then, students elaborate their own forecasts. To produce reports, students must be able to predict which sunspots may be a source of solar storms, discover when solar storms occur and predict which ones will affect Earth, measure disturbances to Earth's magnetic field and predict auroras, know when to watch for auroras, and share the news as professional space weather alerts. They can use video/audio equipment or email information to colleagues.

Data collection is performed weekly. Teams use SWAC clipboards or notebooks to document space weather data at their action centers. Daily data collection is 
recommended if the curriculum time allows a minimum of 2-3 times a week. If journaling is not done on a daily basis, students need to review the space weather data from previous days to stay current.

Students should circulate through each section by rotating groups on a weekly basis, because this allows them to learn about each section, continue to collect and analyze data, make first-hand observations about how the data changes over time, and gain experience in broadcasting. By sharing and graphing the data over a month-long period, they can look for patterns or trends in the data and develop a deeper understanding of targeted concepts. Small groups of 2-4 students can rotate and share data collection responsibilities. However, the entire group can take part in the optional reporting out and/or broadcasting component.

\subsubsection{The Lesson}

The lesson is divided in phases that follow a logical sequence of pedagogical procedures.

1. Engage (30 minutes): The teacher conducts discussions with students to access their prior knowledge about the Sun, connecting it to topics to be learned, aiming to motivate students to activities to come.

2. Explore (45 minutes): Students are divided in four teams, corresponding to the four SWAC areas, to explore material and content.

3. Explain (45 minutes): Teams share with the entire class their expertise about the Sun and space weather acquired from the previous phases, and produce a report on their specific area.

4. Elaborate 90 minutes (Initial Startup Assemble): Students design, assemble and use an action center. Completed display boards are often used as backdrop for the learning center and are placed behind computers used to access SWAC data. In this phase, students apply concepts they have learned, establish connections with related concepts, and apply their understandings to the world around.

5. Evaluate (20 minutes): There is a link provided at the SWAC Web site containing several suggestions on how to promote the continuous assessment of student learning.

\subsubsection{Preparing Reports}

With their new action centers assembled, students should be assigned to one of the following five subject area groups: a) Sunspot Regions (1-5 students); b) Storm Signals (1-5 students); c) Magnetosphere (1-5 students); d) Auroras (1-5 students); e) Broadcasting (1-5 students)

Teams can have four students working as data miners, while one student from each group acts as data analyst. Data miners collect and record all information needed on the data collection sheet specific to their assigned subject area. The data analyst in each group monitors student data sheets, summarize information and fill in the required information on the space weather script. In each group, students can share or rotate data collection responsibilities for their specific subject area.

A sample script is provided, so that students fill in the missing pieces based on data collected in their student journals. Updates for each section of the script can be taken 
from data collection sheets. Students should include images when possible. After all groups have filled in the required information on the script template, it can be given to the broadcast team who develop and present the information as a comprehensive space weather news report.

Students should dedicate some 15 minutes per day to collect data for their station and some 15 minutes per week to produce a space weather report. They should be encouraged to present reports as space weather broadcasts. These brief reports can be presented through various accessible media, including inexpensive video editing software and/or already existing school-based broadcast studios.

\subsubsection{Real-Time Broadcasting}

Students are encouraged to transform their SWAC reports into regularly scheduled news reports, which can be presented through accessible media including inexpensive video editing software. Materials required:

- One (1) additional Internet capable computer and desk;

- One (1) Webcam or camcorder;

- One (1) wall area for use of a 5 by 6 foot green screen or backdrop;

- Audio/Video Recording Software: There is a variety of software options available, including SONY Vegas Movie Studio, Adobe's Visual Communicator 3 (VC3), CCTV, iMovie, Audacity, Garage Band, etc.

The SWAC Web site includes sample scripts, video clips, sample reports, teacher guides, downloadable graphics, etc. These additions are needed to use video broadcasting or movie editing software. A sample Space Weather video report can be viewed on the SWAC Web site.

\section{Conclusions}

Space education at NASA is a complex enterprise that has been offering many benefits for STEM education. The "portfolio" of investments in different programs, technologies, didactic resources, Web-based material, courses and more maintains a focus on the agency's efforts while offering the educational community a variety of products to fit their specific needs and interests. NASA online resources benefit both national and international educational communities. Currently, however, STEM education in the U.S. overemphasizes national assessment. National evaluations tend to focus on some content such as mathematics and language, somehow discouraging teachers from investing more time in teaching STEM content more fully. Additionally, as the number of school hours devoted to STEM education reduces, teachers need to become more selective about which contents to teach and, again, space education loses "space." In this panorama, debates between NASA and the Department of Education should be encouraged in the sense that proper space-related content and practices could benefit STEM curricula at a national level.

In this paper we explore the Space Weather Action Center (SWAC) Program, which presents a pedagogical approach that takes advantage of motivating tools such as video and broadcasting to capture students' emotion to subjects explored. When students are emotionally engaged in a task, they perform better [13]. Activities contemplate important aspects of STEM education, such as high-level thinking, 
teamwork, communication, and more. SWAC also encourages students to act like professional scientists, and students feel responsible for the accuracy and communication quality of their work, as they will be "on the screen!" We here suggest some tools that could enhance the program. For example, conceptual maps [14] could help access students' understanding of space weather concepts before, during and after activities are over. Teacher could gradually accompany how students are retaining and correctly linking concepts, in hierarchical levels.

There is controversy between pedagogical theories targeted to STEM education. Some of them encourage students to construct their knowledge autonomously, and others state that proper guidance is fundamental to achieve learning, especially if students still do not have substantial prior knowledge in a given field [15]. The SWAC Program covers both aspects, as there are moments in which students receive full guidance to conduct their activities, and there are other moments in which they should work autonomously in collecting, analyzing and reporting data. Actually, we see guidance and autonomous work as complementary to each other, and SWAC provides both dimensions in a balanced manner. Considering the great potential of the SWAC architecture, both its structure and content could be applied to many other topics and translated to other languages.

As society becomes increasingly complex and dynamic, education should accompany such transformations in order to be effective. Space education at NASA offers singular contributions to STEM education and we need to be more emphatic in our efforts to make of it a curricular, systematic practice, as well. However, educators must be closely involved in the process. While curricular negotiations evolve between agencies and stakeholders at all levels, we should focus on student needs along with pre- and in-service courses for teachers in space education topics. These courses should consider the level of understanding of teachers in areas to be covered. In other words, we need to speak their language. Interdisciplinary teams of scientists and educators are fundamental in this enterprise. For example, this year, as we celebrate the International Year of Astronomy (IYA), we need to engage students and educators to view both the Earth and the Universe in new ways. In summary, we all need to keep strengthening our educational efforts, and simultaneously seek more "space" for space education, as this area offers singular pedagogical benefits for STEM education.

\section{Acknowledgements}

We are thankful to Dr. Shelley Canright, Manager of Elementary, Secondary and e-Education at NASA Headquarters, for her singular contributions in providing valuable suggestions for the NASA Education and Educational Technologies section of this paper.

Ms. Reis, in particular, extends thanks to NASA Goddard Space Flight Center for hosting her in summer 2008 as a science education intern through the International Space University - ISU.

\section{References}

[1] Waack, R.S., Amoroso, S.: Desenvolvendo sustentabilidade. Parcerias Estratégicas 20, 451-458 (2005), http://www.cgee.org.br/arquivos/p_20_1.pdf (accessed February 15, 2009) 
[2] Reis, N.T.O., Garcia, N.M.D., Souza, P.N., Baldessar, P.: Análise da dinâmica de rotação de um satélite artificial: uma oficina pedagógica em educação espacial. Revista Brasileira de Ensino de Física 30(1), 361-371 (2008),

http: / / www.sbfisica.org.br/rbef/pdf/301401.pdf

(accessed March 15, 2009)

[3] OECD: PISA 2006 science competencies for tomorrow's world. OECD Publishing, Paris (2006)

[4] André, C.F.: A prática da pesquisa e mapeamento informacional bibliográfico apoiado por recursos tecnológicos: impactos na formação de professores (Doctoral thesis). Academic advisor: Stela Conceição Bertholo Pinonez. São Paulo, SP, Faculdade de Educação da Universidade de São Paulo - USP (2009)

[5] Rosendhal, J., et al.: The NASA Office of Space Science Education and Public Outreach Program. Advances in Space Research 34, 2127-2135 (2004)

[6] Andrew, F.: Space science education in the United States: The good, the bad and the ugly. In: Steven, J.D., Roger, D.L. (eds.) Societal impact of spaceflight, NASA, Office of External Relations, History Division, Washington, DC, pp. 407-419 (2007)

[7] NASA: NASA education program, NASA, Education Division, Washington, DC (1993).

[8] NASA: NASA education communication strategy, NASA, Washington, DC (2008), http: / /www.pc.spacegrant.org/Communication.pdf (accessed March 3, 2009)

[9] NASA: NASA 101 - From Vision to reality, NASA, Washington, DC (2007)

[10] Reis, N.T.O.: Pedagogical Analyses of Current Space Science Education Practices at NASA and the Brazilian Space Agency (Masters project). Academic advisor: Walter Peeters. Strasbourg (France), International Space University (2008)

[11] The National Academies Press: The Sun to the Earth and Beyond: A Decadal Research Strategy in Solar and Space Physics. Solar and Space Physics Survey Committee, National Research Council Washington, DC (2003), http: / /www. nap.edu/catalog/10477.html (accessed February 12, 2009)

[12] Garcia, L., Eastman, T.: Space weather. About Plasmas, Available via The Coalition for Plasma Science (2009), http: / / www.plasmacoalition.org (accessed February 20, 2009)

[13] O’Regan, K.: Emotion and E-learning. Journal for Asynchronous Learning Networks JALN 7(3), 78-92 (2003),

http: / /www.sloan-c.org/publications/jaln/v7n3/pdf /

v7n3_oregan.pdf (accessed February 15, 2009)

[14] Novak, J.D., Canas, A.J.: The theory underlying concept maps and how to construct and use them. Technical Report IHMC Cmap Tools 2006-01 Rev 01-2008, Florida Institute for Human and Machine Cognition (2008),

http: / / cmap.ihmc.us / Publications /ResearchPapers /

TheoryUnderlyingConceptMaps .pdf (accessed February 10, 2009)

[15] Kirschner, P.A., Sweller, J., Clark, R.E.: Why minimal guidance instruction does not work: An analysis of the failure of constructivist, discovery, problem-based, experiential, and inquiry-based teaching. Educational Psychologist 41(2), 75-86 (2006) 